\title{
Cristianismo e Educação
}

Sérgio Gonçalves Mendes ${ }^{1}$

\section{Introdução}

Neste artigo pretendemos analisar a relação entre a tradição cristã e a educação em linhas muito gerais. Por uma questão de brevidade, nos impusemos: limitar o estudo ao cristianismo católico, ainda que muitas vezes as reflexões também compreendam a tradição ortodoxa e protestante; tratar principalmente da educação formal; não tratar em particular das especificidades da educação no Brasil.

Após uma análise genérica da educação cristã desde a Antiguidade até o presente, aprofundamos sobre o sentido mais teológico da educação, especificamos o próprio da educação cristã católica, apresentamos a resposta da Igreja Católica ao desafio da educação no contexto de uma sociedade plural, e concluímos com as possibilidades abertas ao cristianismo e a outras religiões pela proposta educativa da Base Nacional Comum Curricular.

\section{A educação cristã: dos monastérios às universidades e um pouco além}

O Cristianismo aparece no horizonte da história dentro de basicamente duas concepções distintas de educação: a judaica e a greco-romana.

Com relação à concepção judaica da educação, o cristianismo herda a preocupação com a leitura dos textos sagrados. Daí a importância da alfabetização, que no caso judaico acontecia no contexto dos estudos sobre as Escrituras nas chamadas "casas de instrução" ou "casas do Livro" (MARROU, p. 406).

Com relação à concepção greco-romana da educação, o ponto de partida é considerar que o cristianismo, ao tornar-se a religião do Império Romano, no século IV, tem diante de si uma cultura marcadamente helênica. Por essa razão, não é casualidade que os escritos do NT sejam muito influenciados pela filosofia e pela literatura gregas, como bem demonstra Werner Jaeger (JAEGER, p. 13-19). O primeiro desafio do cristianismo nascente é justamente o de formar o ser humano novo e espiritual como membro do Reino de Deus, num contexto em que essa doutrina de matriz judaica não seria facilmente compreendida. Por isso há uma apropriação criteriosa de elementos da paideia grega, isto é da cultura e educação gregas, para a formação de uma paideia cristã (JAEGER, p. 35). Essa educação cristã a partir do séc. IV, especialmente aquela destinada aos jovens, constitui-se de estudos selecionados da retórica, da filosofia e da literatura grega, além naturalmente das Escrituras Cristãs. A educação cristã desenvolvida especialmente entre o século IV e $\mathrm{V}$ pode ser definida com um verdadeiro humanismo cristão que será retomado no Renascimento (JAEGER, p. 139). Até o século VII o que mais se assemelhava a uma escola na tradição cristã era o Catecumenato, período de aproximadamente três anos, no qual o convertido era iniciado à doutrina e aos

\footnotetext{
1 Teólogo, professor do Setor de Cultura Religiosa da PUC-Rio, coordenador de pastoral e gestor administrativo escolar.
} 
mistérios da fé cristã. Embora essa educação fosse estritamente religiosa, os catecúmenos participavam da formação escolar pagã existente. No entanto, é digno de nota que nas terras do Império Romano em que não havia escolas estabelecidas, foi justamente o cristianismo quem as promoveu. Foi o que ocorreu na Etiópia, Armênia, Georgia e mais tarde nos países germânicos e eslavos. Nessas escolas se mantinham os estudos da literatura e cultura gregas, uma vez que a própria Bíblia já havia sido traduzida ao grego.

No período do século IV ao VIII, a educação clássica continua uma aliada da expansão do cristianismo. Surgem também nesse período as escolas ligadas aos monastérios. No entanto, por todo esse período a educação cristã ainda se destina à aristocracia. A partir do século $V$, através da influente obra "Mercúrio e a filologia" de Marciano Capella, a formação clássica nos meios cristãos ficou reduzida a sete áreas: gramática, retórica, lógica, aritmética, geometria, astronomia e música. Ele excluiu dessa lista a arquitetura e a medicina, que estavam incluídas na educação superior romana.

Além das escolas monásticas, havia na Idade Média muitas escolas paroquiais e episcopais (ou catedralícias). As escolas monásticas predominaram até o século XI, e depois de então as escolas catedralícias, que a partir do século XII começaram a converter-se em Universidades. Não obstante a existência dessas escolas, a quase totalidade do povo era analfabeta, como boa parte do clero também. No final do século XV já havia cerca de 75 universidades espalhadas pela Europa. Mas é especialmente a partir do século XVI que o movimento renascentista propiciará a formação das escolas de nível médio e a Reforma Protestante as chamadas escolas populares, ocasionando a reação católica através das escolas secundárias dos jesuítas. Outras ordens religiosas católicas também se dedicaram à educação secundária: os barnabitas, os oblatos, as ursulinas, os oratorianos e os escolápios. Ao longo da Idade Moderna, tanto no contexto protestante quanto católico multiplicaram-se as instituições dedicadas à educação primária, secundária e superior. (ABBAGNANO, p. 133-179)

No século XVII, a llustração, movida pelo ideal do liberalismo político, econômico, moral e religioso, representou a definitiva separação entre a educação e a religião. Alimenta-se então o ideal de uma escola laica (não religiosa) e livre (independente dos privilégios de classe). Aqui também o ideal humanista da educação acaba cedendo ao pragmatismo da formação para as ciências, técnicas e ofícios. (ARANHA, p. 286)

No entanto, a partir da Idade Moderna, com todas as rupturas históricas entre a Igreja e - Estado, mesmo a educação dita laica ou civil continua a conservar estruturas que se remetem às academias protestantes e aos colégios da Companhia de Jesus, como reconhece Marrou no século XX. (MARROU, p. 8)

$\mathrm{Na}$ atualidade, assistimos a coexistência das escolas confessionais e laicas. O cristianismo não abandonou a educação, cada vez mais entendida como parte da missão global da evangelização. Isso não significa, no entanto, que a educação seja entendida pelos cristãos como uma estratégia proselitista. Antes, a educação é compreendida como uma das 
formas privilegiadas de promover os valores da Evangelho, tais como a fraternidade, a justiça e a paz.

\section{A Revelação como pedagogia divina}

O cristianismo surge a partir da livre iniciativa de Deus de se revelar através dos patriarcas e profetas do povo de Israel, conforme registrado nos livros do Antigo Testamento. Para os cristãos, o ápice dessa autorrevelação de Deus se encontra na pessoa de Jesus de Nazaré. No entanto, é curioso notar que o Deus judeu-cristão não está muito preocupado em revelar "doutrinas" ou "verdades", antes, convida a uma aliança com Ele. A grande revelação é o próprio desejo de Deus de estabelecer um pacto de amor com o seu povo. É no horizonte dessa aliança fundamental, iniciada na figura de Abraão e renovada ao longo da história que se descortina outra revelação: o próprio ser de Deus. É na história que o Deus de Abraão, Isaac e Jacó se dá a conhecer. E o conhecimento de Deus se revela, ao mesmo tempo, o conhecimento de quem verdadeiramente é o ser humano. Os discípulos de Jesus de Nazaré seguem aprofundando esse conhecimento do mistério de Deus e do próprio ser humano.

Há, portanto, uma pedagogia da revelação de Deus. Ele se utiliza dos eventos e das palavras humanas para dar a conhecer a sua vontade. Deus apresenta seu plano salvífico em etapas progressivas que permitem ao povo de Israel e, posteriormente, aos cristãos, adentrarem o seu mistério de amor (CONGREGAÇÃO PARA O CLERO, n. 38).

A vida e as palavras de Jesus aprofundam essa pedagogia divina:

Vinda a plenitude dos tempos, Deus mandou à humanidade Seu Filho, Jesus Cristo. Ele trouxe ao mundo o supremo dom da salvação, realizando a sua missão de redentor, no âmbito de um processo que continuava a « pedagogia de Deus » com a perfeição e a eficácia intrínsecas à novidade de sua pessoa. Das suas palavras, sinais e obras, ao longo de toda a sua breve mas intensa vida, os discípulos fizeram experiência direta das diretrizes fundamentais da " pedagogia de Jesus ", indicando-as, depois, nos Evangelhos: o acolhimento do outro, em particular do pobre, da criança, do pecador, como pessoa amada e querida por Deus; o anúncio genuíno do Reino de Deus como boa nova da verdade e da consolação do Pai; um estilo de amor delicado e forte, que livra do mal e promove a vida; o convite premente a uma conduta amparada pela fé em Deus, pela esperança no reino e pela caridade para com o próximo; o emprego de todos os recursos da comunicação interpessoal tais como a palavra, o silêncio, a metáfora, a imagem, o exemplo e tantos sinais diversos, como o faziam os profetas bíblicos. Convidando os discípulos a segui-Lo totalmente e sem nostalgias, (38) Cristo entrega-lhes a sua pedagogia da fé como plena compartilha da sua causa e do seu destino ${ }^{2}$.

Assim, a práxis de Jesus é interpretada como uma pedagogia divina a ensinar-nos a verdadeira humanidade a qual toda pessoa humana é chamada a realizar ao longo de sua vida. Entende-se, portanto, que a educação cristã não almeja outra coisa que colaborar para a formação de uma humanidade nova, à imagem de Cristo. Daí que o primeiro ambiente educativo reconhecido pela tradição cristã como o mais importante é a própria família.

${ }^{2}$ Cf. CONGREGAÇÃO PARA O CLERO. Diretório Geral para a Catequese, n. 140. 
(CONGREGAÇÃO PARA A EDUCAÇÃO CATÓLICA, 2007, n. 12). Convém notar que a pedagogia de Jesus se manifesta de modo eminentemente ético: o amor ao próximo como expressão do amor de Deus e do amor a Deus. Aqui se delineia um traço identitário de uma verdadeira educação cristã: formar homens e mulheres que encarnam em sua práxis cotidiana os mesmos valores de Jesus de Nazaré.

\section{A educação cristã católica}

A finalidade da educação católica, em todas as suas modalidades, é a promoção da pessoa humana, o que implica em uma educação integral, que "não apresenta só conhecimentos a adquirir, mas também valores a assimilar e verdades a descobrir" (CONGREGAÇÃO PARA A EDUCAÇÃO CATÓLICA, 1997, n. 9-14).

Para atingir o fim da educação cristã católica faz-se necessária uma nova antropologia, que compreenda e atinja a totalidade da pessoa: como ser de memória; como ser de relação consigo, com os outros, com o cosmos e com Deus; como ser de promessa, capaz de colaborar na construção de um novo mundo, marcado pela ecologia integral, em que o desenvolvimento sustentável se faz acompanhar pela luta em prol da justiça global (CONGREGAÇÃO PARA A EDUCAÇÃO CATÓLICA, 2014, cap. III).

\section{A educação cristã numa sociedade plural}

Embora desde o Concílio Vaticano II (1963-1965) a Igreja Católica tenha cada vez mais se pronunciado favorável ao ecumenismo, ao diálogo inter-religioso, ao caráter laico do Estado e ao pluralismo da sociedade pós-moderna, ela não tem, por outro lado, se furtado ao dever de denunciar valores e ideologias que mais do que afrontar a fé cristã, configuram-se, desde o ponto de vista católico, como uma afronta à dignidade humana.

Por essa razão, a educação cristã católica é bastante crítica quanto a algumas tendências da cultura atual tais como o hedonismo, o relativismo, o consumismo, a crescente desagregação da família, o recrudescimento de várias formas de violência como os preconceitos de todos os tipos, o fundamentalismo, o terrorismo, as agressões ao meioambiente, a perpetuação da miséria e da exclusão de milhares de povos, etc.

Diante desse cenário a educação cristã católica busca formar não apenas para a tolerância, mas, sobretudo, para a comunhão (CONGREGAÇÃO PARA A EDUCAÇÃO CATÓLICA, 2007, n. 39), diante da "emergência educativa" de nosso mundo:

A cultura atual é permeada por várias problemáticas que provocam uma difusa "emergência educativa". Com esta expressão, nos referimos à dificuldade em estabelecer relações educativas que, para serem autênticas, devem transmitir às jovens gerações valores e princípios vitais, não só para ajudá-las a crescer e amadurecer individualmente, mas também para contribuir na construção do bem comum. A educação católica, com as suas numerosas escolas e 
universidades espalhadas pelo mundo, dá um contributo relevante às comunidades eclesiais comprometidas na nova evangelização, e contribui também para que as pessoas e a cultura assimilem os valores antropológicos e éticos que são necessários para construir uma sociedade solidária e fraterna ${ }^{3}$.

Nesta citação já aparece a compreensão da educação como um bem comum, bem na perspectiva da educação como um direito humano universal. Essa compreensão educativa foi relevantemente defendida por Paulo VI na Declaração Gravissimun educationis ${ }^{4}$ e pela Constituição Pastoral Gaudium et Spes ${ }^{5}$ do Concílio Vaticano II. Em tais documentos acrescenta-se ainda a condenação da subserviência da cultura e da educação ao poder econômico e às suas lógicas; a defesa da participação da mulher na vida cultural; e a defesa da construção de um novo humanismo.

Apesar desses esforços da Igreja Católica, assiste-se ainda à suspeita sobre suas intenções e propostas educativas. Daí o protesto de Joaquín G. Roca: "A educação cristã não é um departamento da empresa católica encarregada de produzir convicções, transmitir competências e reproduzir os sentimentos próprios de um universo simbólico" (ROCA, p. 10). Mas a suspeita sobre a educação católica, algumas vezes, se aguça em função de algumas concepções do Ensino Religioso. Com efeito, existem basicamente três modelos de educação religiosa escolar: o catequético, cuja variante é o ensino ecumênico, em que há o ensino explícito da confissão cristã, acentuado algumas vezes por um viés apologético e até proselitista; o fenomenológico em que as religiões são todas tratadas em igualdade de condições, sem privilegiar nenhuma em particular; e o da educação da religiosidade, que visa o cultivo da abertura à Transcendência, pressuposta como inerente a todo ser humano (XAVIER, p. 19-20). Sobretudo em relação ao primeiro modelo há a suspeita de que a educação cristã, tanto católica quanto protestante, intenciona basicamente o aumento do número de fieis, através da camuflada estratégia da oferta de serviços educativos. Essa suspeita naturalmente não pode ser generalizada, ainda que em alguns casos pareça ser efetivamente bastante plausível.

Há que se ter, com relação ao tema da relação entre cristianismo e educação, certa paciência histórica. As mudanças nas instituições milenares são sempre lentas e ao descompasso das mudanças da sociedade, especialmente nesses "tempos líquidos" em que a volatilidade se contrapõe a toda pretensão de certeza ou de verdade. Apesar disso é importante salientar a crescente consciência eclesial sobre uma nova forma de compreender a educação:

${ }^{3}$ Cf. CONGREGAÇÃO PARA A EDUCAÇÃO CATÓLICA. Educar hoje e amanhã uma paixão que se renova, Introdução.

4 Cf. PAULO VI. Carta Encíclica Gravissimun educationis. Vaticano, 1965. Disponível em: http://www.vatican.va/archive/hist councils/ii vatican council/documents/vat-ii decl 19651028 gravissimumeducationis po.html. Acesso em 5 de jun. 2017.

5 Cf. CONCÍLIO VATICANO II. Constituição Pastoral Gaudium et Spes. Vaticano, 1965. Disponível em: http://www.vatican.va/archive/hist councils/ii vatican council/documents/vat-ii const 19651207 gaudium-etspes po.html. Acesso em 5 de jun. 2017. 
A escola e a universidade são lugares de educação à vida, ao desenvolvimento cultural, à formação profissional, ao empenho pelo bem comum; representam uma ocasião e uma oportunidade para compreender o presente e para imaginar o futuro da sociedade e da humanidade. A raiz da proposta formativa é o patrimônio espiritual cristão, em constante diálogo com o patrimônio cultural e as conquistas da ciência. Escolas e universidades católicas são comunidades educativas nas quais a experiência de aprendizagem se alimenta da integração entre pesquisa, pensamento e vida ${ }^{6}$.

Vê-se nessa citação uma clara abertura ao diálogo com a pluralidade que marca o contexto pós-moderno. Naturalmente que o diálogo supõe a consciência da própria identidade religiosa. Negá-lo seria um arremedo de diálogo, na medida em que a identidade religiosa vivida e assumida, seria artificialmente dissimulada a fim de favorecer uma melhor acolhida. A própria fé em Deus Trino, artigo central do credo cristão, supõe a unidade divina na diversidade de pessoas. Nossa imagem e semelhança com Deus Trino conduz-nos e exige-nos a comunhão em que a diversidade é condição para a unidade, não um empecilho.

\section{BNCC e Cristianismo}

A Base Nacional Comum Curricular (BNCC) elaborada de modo bastante participativo desde 2015, encontra-se agora, em 2017, em sua terceira e definitiva versão. A BNCC "é um documento de caráter normativo que define o conjunto orgânico e progressivo de aprendizagens essenciais que todos os alunos devem desenvolver ao longo das etapas e modalidades da Educação Básica"7 . Nela se estabelecem dez competências gerais que devem perpassar todas as áreas de conhecimento. Chama à atenção nessas competências a contínua referência a valores éticos a serem desenvolvidos e defendidos: liberdade, autonomia, consciência crítica, responsabilidade, cuidado, autoconhecimento, empatia, diálogo, respeito, acolhida à diversidade, compromisso, flexibilidade, resiliência, determinação e solidariedade.

Mais eloquente ainda a esse respeito é a reflexão que se segue à apresentação das dez competências gerais:

Ao definir essas dez competências, a BNCC assume que a "educação deve afirmar valores e estimular ações que contribuam para a transformação da sociedade, tornando-a mais humana, socialmente justa e, também, voltada para a preservação da natureza". Tais competências representam um "chamamento à responsabilidade que envolve a ciência e a ética", devendo constituir-se em instrumentos para que a sociedade possa "recriar valores perdidos ou jamais alcançados". Em síntese, esse conjunto de competências explicita o compromisso da educação brasileira com a formação humana integral e com a construção de uma sociedade justa, democrática e inclusiva ${ }^{8}$.

Ora, a própria BNCC faz referência às religiões como parte constitutiva da pluralidade da sociedade. Mas cabe, indo além deste documento, afirmar que não apenas o cristianismo,

\footnotetext{
${ }^{6}$ Cf. CONGREGAÇÃO PARA A EDUCAÇÃO CATÓLICA. Educar hoje e amanhã, cap III, 1, "e").

${ }^{7}$ Cf. BNCC, p. 7. Disponível em: http://basenacionalcomum.mec.gov.br/images/BNCC publicacao.pdf. Acesso em 5 de jun. 2017.

${ }^{8}$ Cf. BNCC, p. 19
} 
mas também as grandes religiões da humanidade foram e são defensoras e promotoras de tais valores. De tal maneira que o esforço educativo, apoiado nos valores elencados, terá seu êxito cada vez mais garantido, quanto mais acolha a contribuição das diversas tradições religiosas. Pois, a despeito de todas as suas possíveis incoerências, as religiões são "peritas em humanidade".

Em particular, o cristianismo católico tem assumido, de modo explícito, a defesa e a promoção desses valores através não apenas das declarações oficiais do Magistério, mas sobretudo através das inúmeras ações educativas e pastorais do Povo de Deus espalhado pelos cinco continentes.

Merece consideração o fato de que, para a educação superior, ainda não se tenha um documento geral que norteie os valores éticos a serem perseguidos nesse nível de educação. Isso pode significar uma vicissitude histórica que talvez tenha resposta em um futuro próximo, ou pode significar uma ausência sintomática de uma deficiência a ser superada. A esse propósito expressa uma vez mais a Igreja Católica:

O esforço do conhecimento e da pesquisa não deve ser separado do sentido ético e do transcendente. Nenhuma ciência verdadeira pode negligenciar as suas consequências éticas e não existe verdadeira ciência que afaste da transcendência. Ciência e ética, ciência e transcendência não se excluem reciprocamente, mas se conjugam para uma maior e melhor compreensão do homem e da realidade do mundo ${ }^{9}$.

\section{Conclusão}

Ao tratarmos da relação entre Cristianismo e Educação faz-se necessário notar que esta relação conheceu, ao longo do tempo, concepções bastante heterogêneas: desde a subserviência da educação à religião cristã até a mútua colaboração.

Se a tarefa primeira da educação é formar mulheres e homens para a vida em sociedade, pautando a práxis por valores éticos fundamentais e necessários à convivência justa e fraterna, faz-se necessário reconhecer que tal esforço educativo não se faz à margem da tradição cristã, uma vez a construção do Reino de Deus almejada por ela, supõe tais valores, ainda que não se reduza a eles. Desse modo, o que ainda falta por fazer é ampliar os espaços de diálogo, nos quais a missão educativa possa ser enriquecida pela contribuição tanto de pessoas religiosas quanto sem religião. Naturalmente que tais esforços não se farão de uma vez por todas, uma vez que a velocidade frenética das mudanças sociais exige, a cada tempo, novas escolhas e decisões. Interessa, em síntese, que a educação em seus mais diversos âmbitos contribua, cada vez mais e melhor, para o crescimento de todos em humanidade.

\section{Para refletir:}

\footnotetext{
${ }^{9}$ Cf. CONGREGAÇÃO PARA A EDUCAÇÃO CATÓLICA. Educar hoje e amanhã, n. II, 2.
} 
1. Embora a educação não deva ser subserviente à religião, não deveria ignorar a contribuição que as religiões podem oferecer. Você concorda? Justifique.

2. Não se educa "para" os valores a não ser educando "com" valores. O que é necessário para educarmos "com" valores? As religiões teriam algum papel nesse contexto?

\section{Bibliografia}

ABBAGnANO, N.; VISALBERGHI, A. Historia de la pedagogía. México: Fondo de Cultura Económica, 1964.

ARANHA, Maria Lúcia de Arruda. História da Educação e da Pedagogia. São Paulo: Moderna, 2012.

CONGREGAÇÃO PARA A EDUCAÇÃO CATÓLICA. A escola no limiar do terceiro milênio. Vaticano,1997. Disponível

em:

http://www.vatican.va/roman curia/congregations/ccatheduc/documents/rc con ccatheduc doc 27041998 school2000 po.html. Acesso em 29 mai. 2017.

CONGREGAÇÃO PARA A EDUCAÇÃO CATÓLICA. Educar hoje e amanhã uma paixão que se renova. Instrumentum laboris. Vaticano, 2014. Disponível em: http://www.vatican.va/roman curia/congregations/ccatheduc/documents/rc con ccatheduc doc 20140407 educare-oggi-e-domani po.html. Acesso em 29 mai. 2017.

CONGREGAÇÃO PARA A EDUCAÇÃO CATÓLICA. Educar juntos na escola católica. Missão partilhada pessoas consagradas e fieis leigos. Vaticano, 2007. Disponível em: http://www.vatican.va/roman curia/congregations/ccatheduc/documents/rc con ccatheduc doc 20070908 educare-insieme po.html. Acesso em 29 mai. 2017.

CONGREGAÇÃO PARA O CLERO. Diretório Geral para a Catequese. Vaticano, 1997. Disponível em

http://www.vatican.va/roman curia/congregations/cclergy/documents/rc con ccatheduc doc 1 7041998 directory-for-catechesis po.html. Acesso em 5 jun. 2017.

JAEGER, Werner. Cristianismo primitivo y paideia griega. 5aㅡ reimpressão. México: Fondo de Cultura Económica, 1965.

MARROU, Henri-Irénée. Historia de la Educación en la Antigüedad. Madrid: Seuil, 1971. ROCA, Joaquín García. A educação cristã no terceiro milênio: o que é, como se faz. São Paulo: Loyola, 1999.

XAVIER, Mateus Geraldo. Contribuição do Ensino Religioso no acesso à fé. São Paulo: Loyola, 2006. 